\title{
Ações para saúde do idoso em nível municipal e sua efetivação na visão dos integrantes da Comissão de Integração Ensino Serviço
}

\author{
Adriana Cristina Hillesheim*, Astor A. Diehl"*, Vanessa da Silva Corralo"**; Clodoaldo Antônio De Sá***
}

\section{Resumo}

O processo de envelhecimento populacional, embora seja um fenômeno mundial, é percebido com mais ênfase em países em desenvolvimento. Isso requer políticas e ações efetivas de atenção à saúde do idoso. Este estudo propôs-se a identificar as ações voltadas para a saúde da pessoa idosa previstas nos Planos Municipais de Saúde (PMS) da Macrorregião Extremo Oeste II de Santa Catarina e sua efetivação na visão dos representantes da Comissão de Integração Ensino-Serviço (Cies). A coleta de dados foi feita com base na análise de documentos disponibilizados pelos municípios e entrevista com 39 representantes da Cies. A análise dos dados demonstrou que das três regionais de saúde pesquisadas apenas uma dispõe dos planos de todos os municípios na página oficial do estado. Nos municípios pesquisados, quatro referem não ter disponibilizado o plano, apesar de tê-lo construído, e dois não o possuem. Dos sujeitos entrevistados, quatro representantes do controle social, um trabalhador do SUS e dois gestores em educação referem não saber se o município tem PMS. Dentre os que afirmaram saber que o município o tem, cinco representantes do controle social, um trabalhador do SUS e três gestores em educação referiram não conhecê-lo. Dentre os municípios pesquisados, seis não preveem ações para a saúde do idoso no PMS. Conclui-se que o desconhecimento do PMS, a não participação em sua elaboração e a sua não utilização como ferramenta de planejamento e avaliação constituem uma fragilidade na efetivação das políticas de promoção de saúde, em especial da saúde do idoso.

Palavras-chave: Saúde do idoso. Gestão em saúde. Planejamento.

* Enfermeira pela Universidade de Passo Fundo, docente do curso de Enfermagem da Universidade Comunitária da Região de Chapecó, mestranda do Programa de Pós-Graduação em Envelhecimento Humano da Universidade de Passo Fundo. Endereço para correspondência: Av. Senador Attílio Fontana, 591-E, Bairro Efapi, CEP: 89809-000, Chapecó - SC. E-mail: adrianah@unochapeco.edu.br.

** Dr. em Teoria, Metodologia e Didática da História pela Ruhr Universitat Bochum, docente do Programa de Pós-Graduação em Envelhecimento Humano da Universidade de Passo Fundo.

*** Dra. em Bioquímica Toxicológica pela Universidade Federal de Santa Maria, docente do Programa de Pós-Graduação em Ciências da Saúde da Universidade Comunitária da Região de Chapecó.

**** Dr. em Ciências do Movimento Humano pela Universidade Federal de Santa Maria, docente do Programa de Pós-Graduação em Ciências da Saúde da Universidade Comunitária da Região de Chapecó.

$\hookrightarrow$ Recebido em setembro de 2012 - Aprovado em outubro de 2012.

$\longrightarrow$ doi:10.5335/rbceh.2012.031 


\section{Introdução}

O processo de envelhecimento populacional é um fenômeno mundial que se dá de maneira mais rápida, sobretudo, nos países em desenvolvimento. Esse fenômeno tem instigado o debate acerca das políticas públicas e das estratégias para o enfrentamento dessa situação. Se, por um lado, o debate vem produzindo avanços em termos de políticas voltadas para a saúde da pessoa idosa, por outro, as ações não têm se traduzido em ganhos de mesma magnitude para esse fim.

No Brasil, o Sistema Único de Saúde (SUS) tem buscado, no âmbito de suas políticas, o contato com a realidade social e com as especificidades regionais. Dessa maneira, o Pacto pela Vida reflete o compromisso entre os gestores em torno das prioridades em relação à saúde da população brasileira. (BRASIL, 2006a). Nesse documento, uma das seis prioridades pactuadas refere-se à saúde do idoso.

As diretrizes do Pacto pela Vida quanto a essa questão contemplam a promoção do envelhecimento ativo e saudável, além de ações visando à integralidade da atenção, com ênfase à educação permanente dos profissionais de saúde focados nessa área. (BRASIL, 2006a). Para tanto, o modelo de assistência adotado é de suma importância, bem como a regulamentação das ações em saúde pelos profissionais, com vistas à promoção à saúde. Tais ações devem constituir uma prática constante, baseada no planejamento e na avaliação.
Aprovada em 2006, a Política Nacional de Saúde da Pessoa Idosa (PNSPI) objetivou promover a atenção adequada à saúde para os idosos brasileiros, tendo como finalidade recuperar, manter e promover a autonomia e a independência dos indivíduos idosos, direcionando medidas coletivas e individuais de saúde para esse fim, em consonância com os princípios e as diretrizes do SUS. (BRASIL, 2006b). Essa política deveria constituir-se em princípio balizador da elaboração do Plano Municipal de Saúde (PMS) e das ações planejadas para os idosos; no entanto, não raramente, a produção do PMS torna-se uma mera formalidade cujo propósito maior é o atendimento dos aspectos legais.

Outra questão importante colocada nos fóruns de debate envolve os mecanismos a serem propostos para garantir a efetividade de ações voltadas para a promoção da saúde do idoso. Consequentemente, muitas dessas ações que devem ser detalhadas em instrumentos de planejamento como o PMS, para identificar e valorar a mudança e o impacto alcançado em razão dos objetivos estabelecidos, não são efetivadas dessa forma, por vezes, pelo desconhecimento dos profissionais de saúde que colocam em prática tais ações.

Quanto ao contexto do SUS e das políticas de atenção ao idoso e ao modo como os municípios organizam-se para pensar, implementar e avaliar estratégias de atenção à saúde do idoso, não foram encontrados, na literatura à qual 
se teve acesso, artigos que abordassem a temática da maneira prevista no presente artigo. Dessa forma, este estudo objetivou identificar as ações voltadas para a saúde da pessoa idosa previstas nos planos municipais e o modo como estas eram efetivadas a partir da visão dos representantes da Comissão de Integração Ensino-Serviço (Cies).

\section{Materiais e métodos}

Trata-se de uma pesquisa exploratória descritiva com abordagem qualitativa. (MINAYO, 2008). A população do estudo foi composta por 39 membros da Cies, que representavam os 25 municípios da Macrorregião Extremo Oeste II de Santa Catarina, registrando-se que cinco municípios não têm representatividade na comissão (Palmitos, Chapecó, Sul Brasil, Nova Itaberaba e Nova Erechim) e que os representantes de um município foram excluídos da pesquisa, pois aderiram à Cies de outra macrorregião do estado. Dessa forma, a amostra foi constituída por 13 trabalhadores do SUS, 9 gestores em saúde, 7 gestores da educação e 10 representantes do controle social.

Para a análise comparativa da relação entre o planejado e o efetivado das ações em saúde para o idoso, a coleta de dados foi realizada em dois momentos. Em um primeiro momento, foi realizada a análise documental para a localização dos planos municipais de saúde e a coleta de dados acerca das ações previstas para a saúde da pessoa idosa em três diferentes fontes: a) a página oficial da Secretaria de Estado da Saúde (SES); b) o setor de planejamento dos municípios; e c) a Quarta Gerência Regional de Saúde. Em um segundo momento, para avaliação das ações efetivadas nos municípios, foram entrevistados os 39 representantes da Cies.

Todos os sujeitos foram informados acerca dos objetivos e procedimentos do estudo e assinaram um Termo de Consentimento Livre e Esclarecido, concordando em fazer parte da amostra. O presente estudo foi aprovado pelo Comitê de Ética em Pesquisa da Universidade de Passo Fundo (UPF) - Parecer n. $052 / 2012$.

\section{Resultados e discussões}

O PMS constitui um instrumento fundamental no processo de avaliação e acompanhamento das ações previstas para a saúde em cada município, principalmente pelo fato de que na sua elaboração participam os gestores, trabalhadores e usuários do SUS. Os dados do presente estudo demonstraram que, das três regionais de saúde pesquisadas, apenas uma dispõe dos planos de todos os municípios na página oficial do Estado. Dentre os 25 municípios pesquisados, 4 referiram não ter disponibilizado o plano, apesar de tê-lo construído, e 2 afirmaram que não possuíam PMS para a gestão 2010/2013.

Segundo a LOS 8.142/90, o não cumprimento dos requisitos estabelecidos para obtenção de recursos para execução 
de ações e serviços de saúde implica que tais subsídios sejam administrados, respectivamente, pelos estados e pela União, perdendo o município a capacidade de gerir os recursos do Fundo Nacional de Saúde (FNS). Dentre os requisitos explicitados nessa legislação para que os municípios recebam os recursos financeiros está o PMS, esse aspecto da legislação tem sido um mecanismo eficaz para pressionar os municípios a elaborarem seus planos municipais de saúde. Por outro lado, os dados deste estudo demonstram que esse processo representa uma mera formalidade para cumprimento de requisitos legais para recebimento de recursos financeiros, contrariando o objetivo do PMS de instrumentalizar o planejamento e o acompanhamento da gestão. (BRASIL, 1990).

Outra questão abordada neste estudo refere-se ao conhecimento sobre as ações previstas no PMS acerca da saúde do idoso pelos representantes da Cies. Dos entrevistados, 4 representantes do controle social, 1 trabalhador do SUS e 2 gestores em educação referiram não saber se o município tem PMS. Dentre os que afirmaram saber que o município o tem, 5 representantes do controle social, 1 trabalhador do SUS e 3 gestores em educação referiram não conhecê-lo. Portanto, esses dados reafirmam a ideia de que, muitas vezes, esse instrumento parece cumprir apenas a exigência legal, já que, apesar de ser obrigatório, segundo a LOS 8.142/90, não está disponível para a população de alguns municípios, o que dificulta o seu uso nos momentos de avaliação. Considerando o número de pesquisados que desconhecem a existência do PMS e aqueles que apenas sabem dessa exigência mas não o utilizam, pode-se afirmar que a construção dos Planos Municipais de Saúde não constitui um processo participativo, contrariando o que preconiza a legislação. Os dados deste estudo fornecem evidências de que o preenchimento do PMS, em parte considerável dos municípios, revela-se uma mera formalidade realizada de forma fragmentada, sem a participação efetiva das equipes que desenvolvem as ações em saúde, minimamente, os membros da Cies.

A consolidação do SUS depende de um planejamento baseado em instrumentos de gestão que contribuam para o melhor aproveitamento das oportunidades e para superação dos desafios, envolvendo a participação dos diferentes atores na definição das metas, bem como no acompanhamento e na avaliação dos resultados alcançados. Faz-se necessário, para tanto, que os atores envolvidos no processo de consolidação do SUS sintam-se não apenas parte do sistema, mas também responsáveis pelo sistema. Contrariamente, nossos dados demonstram o não envolvimento dos membros das Cies nesse processo, visto que uma parcela considerável desses sujeitos desconhece a existência do PMS, e, dentre os que sabem da existência do plano, mais de $30 \%$ não conhecem seu conteúdo e mais da metade não participou de sua elaboração. 
Em relação às ações previstas para a saúde do idoso, observou-se que, entre os municípios pesquisados que possuem PMS, 6 não as contemplam no Pacto pela Vida. (BRASIL, 2006a).

Na perspectiva de que a priorização das ações deve partir dos problemas locais e de que o planejamento também deve ser pensado com base nas necessidades da população, os dados deste estudo apontam para a fragilidade dos processos atuais, visto que a quase totalidade dos PMSs que possuem ações voltadas à saúde do idoso replicam, em seu planejamento, apenas o previsto na legislação.

Mesmo que, na prática, 36 dos 39 entrevistados refiram que são realizadas ações para a saúde do idoso em seu município, essas não são compatíveis com as descritas no PMS e não atendem às diretrizes da PNSPI. Entre as ações referidas pelos sujeitos, destacam-se: atendimento ao hipertenso e diabético, vacinação, campanhas pontuais e priorização do atendimento, as quais não se caracterizam como específicas para a saúde do idoso.

De modo geral, o presente estudo evidenciou um grande descompasso entre o que está previsto na legislação específica, o que se planeja em nível municipal e o que de fato é realizado em termos de políticas de atenção ao idoso.

\section{Conclusões}

Os resultados deste estudo demonstraram que, embora a maioria dos municípios possua o PMS com ações para a saúde do idoso descritas, conforme preconiza a legislação, na prática, as ações desenvolvidas não refletem o conteúdo do plano.

Ainda que os membros da Cies representem segmentos importantes no que diz respeito ao planejamento em saúde, uma parte considerável desses sujeitos desconhece a existência do PMS, demonstrando que a sua construção não constitui um processo participativo como preconizado na legislação. Considerando que os membros da Cies formam a comissão que define as ações para a educação permanente em saúde e a alocação de recursos financeiros para esse fim, o desconhecimento do PMS, a não participação em sua elaboração e a sua não utilização como ferramenta de planejamento e avaliação apontam para uma fragilidade no sistema no que tange à efetivação das políticas de promoção de saúde, sobretudo da saúde do idoso. 


\section{Actions for the elderly population at the municipal level and its implementation in the view of members of the Teaching-Service Integration Commission}

\section{Abstract}

The people aging process is a worldwide phenomenon, especially in developing countries. This requires effective policies and actions of healthcare for the elderly. This study aimed to identify the actions for the health of the elderly provided in municipal health plans (MHP) of Santa Catarina State and its implementation in the view of the Integrated Study-Service Commission (IESC). Data collection was based on analysis of documents provided by municipalities and interviews with 39 members of the IESC. Data analysis showed that among the three regional health centers that was investigated, only one has the plans of all municipalities in the State's official homepage. In municipalities surveyed, four refer not available the plan despite to have it prepared. Two municipalities do not have MHP. Of the subjects interviewed, four representatives of social control, one worker of the National Health Service (NHS), and two education's managers does not refer know if the municipality has HMP. Among those who reported to know that the municipality has HMP, five representatives of the social control, one worker of the NHS, and three education's managers said that they didn't know it. Among the municipalities studied, six have no actions planned for the health of the elderly described in HMP. We conclude that the unknown of SMP, the non-participation in its elaboration, and the non-use of it as a tool for planning and evaluation, constitute fragility in the execution of policies to health promotion.

Keywords: Elderly health. Health management. Planning.

\section{Referências}

BRASIL. Lei n. 8.142, de 28 de dezembro de 1990. Dispõe sobre a participação da comunidade na gestão do Sistema Único de Saúde (SUS) e sobre as transferências intergovernamentais de recursos financeiros na área da saúde e dá outras providências. Diário Oficial da União, Brasília, 31 dez. 1990. p. 3.

Ministério da Saúde. Secretaria-Executiva. Coordenação de Apoio à Gestão Descentralizada. Diretrizes operacionais para os pactos pela vida, em defesa do SUS e de gestão. Brasília: Ministério da Saúde, 2006a. p. 72.

. Política Nacional de Saú-

de da Pessoa Idosa. Brasília: Ministério da Saúde, 2006b. p. 19.

INSTITUTO BRASILEIRO DE GEOGRAFIA E ESTATÍSTICA (IBGE). Censo demográfico de 2010. Primeiros resultados definitivos do censo 2010: população do Brasil é de 190.755.799 pessoas. Disponível em: <http:// www.ibge.gov.br/home/presidencia/noticias/ noticia_visualiza.php?id_noticia $=1866 \& i d$ pagina=1>. Acesso em: 14 fev. 2012.

MINAYO, M. C. de S. O desafio do conhecimento: pesquisa qualitativa em saúde. 12 . ed. São Paulo: Hucitec, 2010.

VENDRUSCULO, C.; CONSTANCI, C.; RÖHRIG, F. A. Introdutório para equipes de saúde da família: uma proposta de educação permanente em saúde no oeste de Santa Catarina. Revista de Saúde Pública, Florianópolis, v. 3, n. 2, p. 77-87, jul. 2010.

YIN, R. K. Estudo de caso: planejamento e métodos. 3. ed. Porto Alegre: Bookman, 2005. 